\title{
Where is syntactic variation?
}

Sjef Barbiers - Meertens Instituut and Utrecht University

\section{Introduction ${ }^{1}$}

Recent years have seen four major developments that have radically changed the field of syntactic variation research. (a) Empirically, dialects have become much more important for this research than they used to be and many large-scale dialect syntax projects have been initiated that seek to provide an extensive overview of the syntactic variation found in a dialect family. (b) At the level of methodology, an important change was not only the large number of informants and locations involved in such dialect projects, but also the incorporation of insights from sociolinguistics into the methodology to deal with accommodation, task effects, gradedness etc. (c) The availability and accessibility of the data has greatly improved thanks to computer and internet technology. (d) Finally, an important development at the theoretical level was the hypothesis put forward in the Minimalist program (Chomsky 1995, 2005) that the syntactic module of the mental grammar is minimal, possibly only consisting of an operation Set Merge ('combine two words/constituents'). This hypothesis implies that there is no variation in the syntactic module. The syntactic variation attested should be the result of the interaction between a small set of fixed, universal syntactic principles and extra-syntactic domains such as the mental lexicon, phonology, pragmatics, processing, memory, the body, and society (cf. the model proposed in (12)).

Together these four developments define a comprehensive program for syntactic variation research. The goal of this paper is to demonstrate the viability and potential fruitfulness of this program. It first discusses the current research infrastructure for dialect syntax research and then concentrates on syntactic doubling to show how syntactic variation arises at the various levels of a language variation model.

\footnotetext{
${ }^{1}$ I would like to thank Jeroen van Craenenbroeck and Göz Kaufmann for comments on an earlier version of this paper. The usual disclaimers apply.
} 


\section{Current infrastructure for dialect syntax research}

\subsection{Large scale dialect syntax projects}

At the moment of writing this paper eleven large scale dialect syntax projects have been completed and thirteen are still running. For a complete overview and descriptions of the individual projects, see www.dialectsyntax.org. ${ }^{2}$ Seven out of the eleven projects completed have resulted in a database. These databases can be searched with the Edisyn search engine, a tool developed at the Meertens Institute (www.meertens.knaw.nl/edisyn/searchengine) ${ }^{3}$ It offers the following functionality: (a) Searching with strings, Parts-of-Speech-Tags and English glosses; (b) Mapping data sets on Google maps; (c) Export functions. The databases searchable by this search engine include: (i) SAND on Dutch dialects (www.meertens.knaw.nl/sand); (ii) ASIT on Italian dialects (http://asit.maldura.unipd.it); (iii) Cordial-Sin on Portuguese dialects （www.clul.ul.pt/en/resources/212-cordial-sin-syntax-orientedcorpus-of-portuguese-dialects); (iv) Nordic corpus of Scandinavian dialects (www.tekstlab.uio.no/nota/scandiasyn/index.html); (v) FRED on English dialects (www2.anglistik.uni-freiburg.de/institut/lskortmann/FRED/); (vi) EMK on Estonian dialects (www.murre.ut.ee/home); (vii) Slovenian dialect syntax database (www.meertens.knaw.nl/edisyn/searchengine).

These databases are of mixed types. While the SAND, ASIT and Slovenian databases involve judgements and translations of test sentences and elicitation, the Portuguese, Scandinavian, English and Estonian collections are corpora of conversations and stories. The geographic distribution of syntactic phenomena in these dialect databases can be mapped by selecting and analyzing the relevant data with the Edisyn research tool. Ideally the results of such selection and analysis projects should be uploaded in applications such as LLMap (www.linguistlist.org), SSWL (Syntactic Structures of the World's languages; sswl.railsplayground.net) and WALS (World Atlas of Linguistic Structures; wals.info)) to make them available to the entire linguistic research community.

\footnotetext{
${ }^{2}$ This website also provides a manual for dialect syntax projects, advising on organizational, methodological and technological aspects of such projects.

${ }^{3}$ The European Dialect Syntax project (2005-2012) was funded by a EURYI-grant (ESF) awarded to Sjef Barbiers (Meertens Instituut).
} 
In the future, databases will be added from projects that are currently running. These include the Scandinavian judgement database (http://www.tekstlab.uio.no/nota/scandiasyn/) and databases on Basque dialects

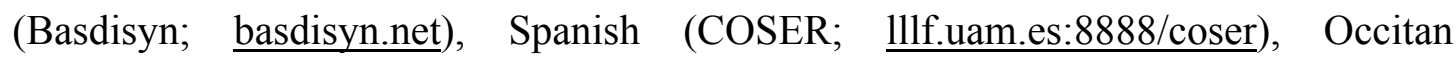
(DADDIPRO), Breton (Arbres; arbres.iker.univ-pau.fr), Alemannic (SynAlm), Welsh (SAWD; lion.ling.cam.ac.uk/david/sawd), American English (YGDP; $\underline{\text { microsyntax.sites.yale.edu }), ~ H e s s i a n ~(S y H D ; ~ w w w . s y h d . i n f o ~})$, and Malagasy.

\subsection{Usability of dialect syntax databases}

The availability of large scale dialect syntax databases greatly enhances the empirical basis of syntactic research. Within theoretical syntactic frameworks such as generative grammar we are currently witnessing a shift away from the methodology of idealization of the data in search of the universal syntactic properties of natural language, towards a methodology that takes into account the full range of syntactic variation that can be found in colloquial language. The ambition of research that adopts the latter type of methodology is higher than that of traditional generative grammar. It seeks to understand syntactic variation in its full complexity, that is as a result of the interaction between fixed syntactic principles and factors at other linguistic levels and at cognitive and social levels.

Another advantage of these databases is that they allow for statistical testing of potential correlations between syntactic properties, a kind of testing that is relatively rare in syntactic research. Examples of such potential correlations are rich agreement and pro drop, agreement as a precondition for displacement, auxiliary doubling and the loss of the simple past, etc. The data in the databases are finegrained, systematic and extensive enough to investigate such correlations at the level of individual members of a paradigm rather than at the level of an entire language, an approach necessitated by the current Minimalist hypothesis that there are no parameters defined over entire languages/dialects and that there is only parametrization at the level of individual lexical items and phonological spell-out.

Since the growing network of dialect syntax databases will extend beyond Indo-European (e.g., Basque, Malagasy), it is also possible to distinguish between correlations that hold within language families and those that hold across them. This is important, because certain correlations may be due to common historical source and 
developments, while others may be due to intrinsic and perhaps universal properties of natural language. The network also allows comparison of dialect families, again a rare type of syntactic research. For example, while many dialects of Dutch have so called long Wh-doubling (1a), none of them has short Wh-doubling (1b) (cf. Barbiers, Koeneman and Lekakou 2009). In Italian dialects, exactly the opposite holds (1c,d) (cf. Poletto and Pollock 2004). ${ }^{4}$ The question is then whether this systematic difference between two dialect families can be derived from some other difference.

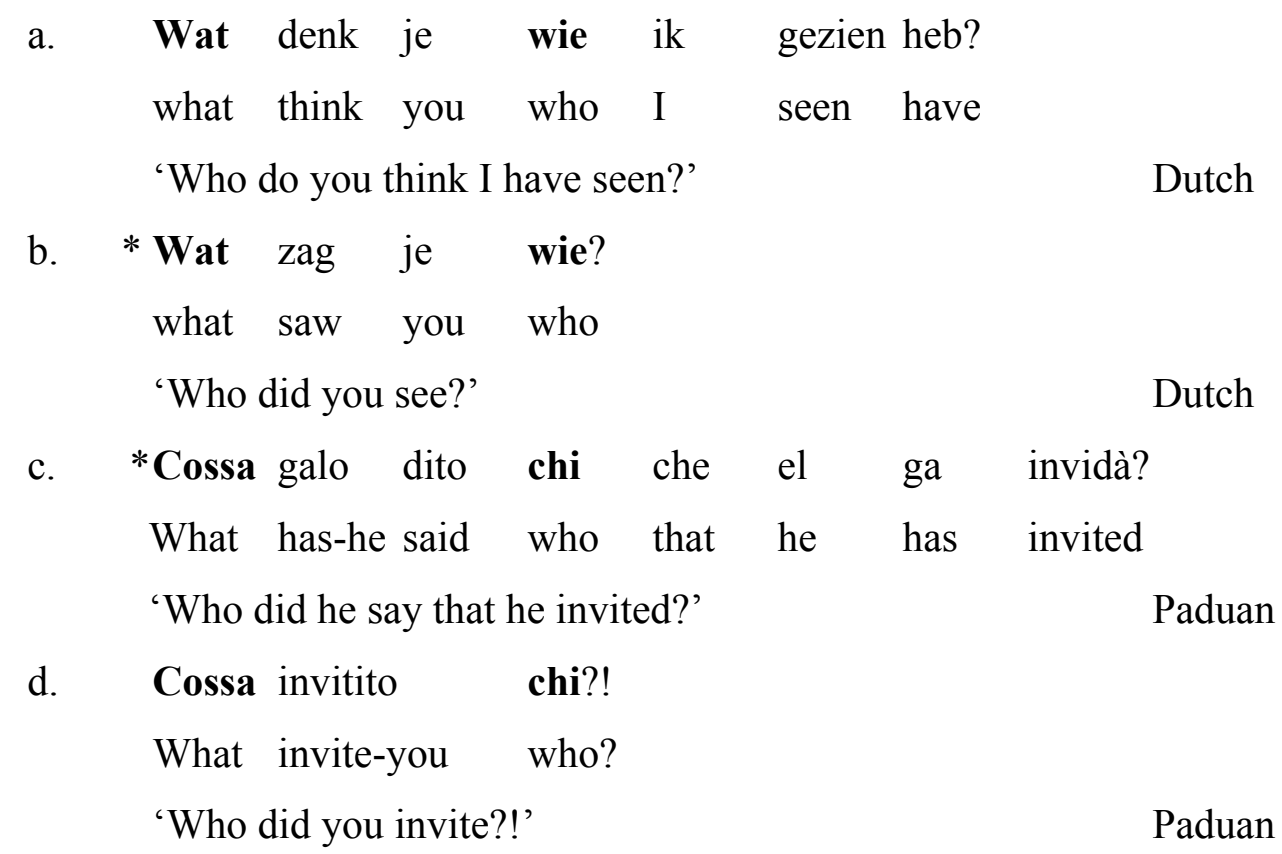

Research of this macro- and mesocomparative type requires interoperability of the databases, i.e. the possibility to search these databases with one common search engine. This is possible with the Edisyn search engine (www.meertens.knaw.nl/edisyn/searchengine) as it comes with a Parts-of-Speech tag constructor that allows the user to search all the databases with self-constructed tags, i.e. with combinations of categories and features. These are automatically translated into the various specific tag sets used for the individual databases (cf. Kunst and Wesseling 2011). In addition, a subset of the databases can be searched with English glosses.

The syntactic data in the dialect syntax databases are geo-referenced. This makes it possible to investigate the relation between geographic patterns and

\footnotetext{
${ }^{4}$ I call this doubling because what is expressed with one Wh-element in Standard Dutch and Italian is expressed by two Wh-elements in the dialects. Cf. infra.
} 
grammatical systems. For example, verb cluster interruption, i.e. the occurrence of a non-verbal constituent between the verbs in a clause-final verb cluster in Dutch is possible with six different types of syntactic constituents in a core area in the south west of the Dutch language area (cf. Barbiers et al. 2008, map 30b). ${ }^{5}$ This is illustrated for definite and bare plural objects in $(2 a, b){ }^{6}$

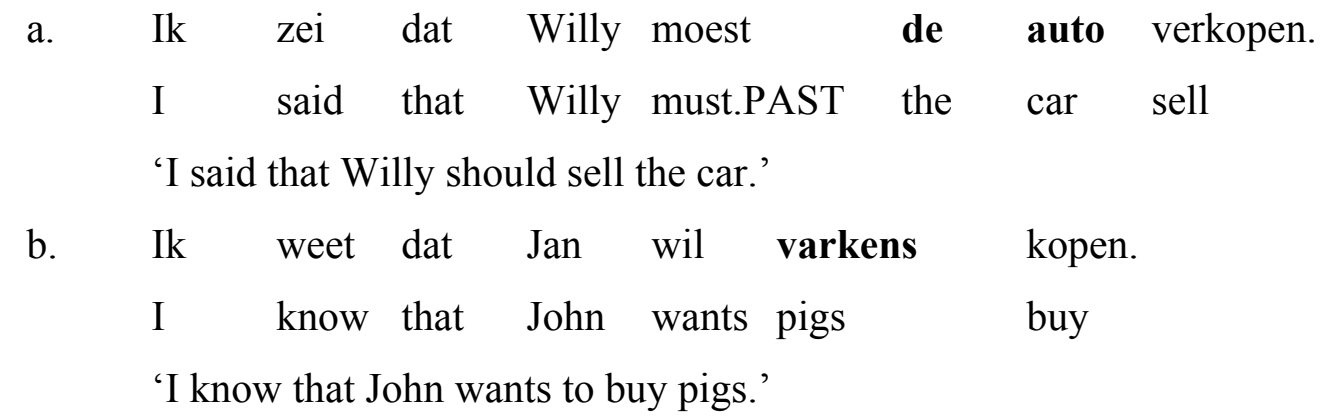

The number of types of syntactic constituents with which this is possible decreases when one moves to the east and to the north. In many locations outside of the core area verb cluster interruption is entirely impossible, i.e. the verbs in a verb cluster are always adjacent. However, when asked for relative judgements, speakers in such locations replicate the geographical pattern. They judge the rarest type of interruption, occurring in the smallest area, to be worse than a type which is less rare etc., and they judge the most common type as relatively (though not completely) acceptable. The question is how this can be explained. Is this due to their familiarity with particular dialect features or with the frequency thereof, an option that is not very likely in view of the Dutch dialect situation, or do speakers have inherent intuitions about markedness?

As was noted above, the Edisyn network of databases contains two types: judgement databases and corpora of spoken conversations and stories. These two types are complementary and are both necessary for dialect syntax research. Judgement databases are particularly suited for categorical, complex or rare syntactic phenomena. They will reveal whether such phenomena occur in a particular dialect or not. The absence of a phenomenon in a spoken corpus of a dialect obviously does not imply the impossibility of that phenomenon in that dialect. On the other hand,

\footnotetext{
${ }^{5}$ For ease of exposition I put aside verb particles that occur inside verb clusters in all Dutch dialects.

${ }^{6}$ Other types of constituents that can interrupt the verb cluster include mass noun objects, indefinite objects, manner adverbs and PP complements.
} 
syntactic research into graded and optional phenomena requires spoken corpora. For example, in the case of two alternative syntactic options we want to know how often and in which circumstances a speaker of a dialect uses option 1 and how often he uses option 2 and whether this proportion is constant across speakers and dialect areas (cf. Fernández-Ordóñez 2010).

Dialect data are only useful if collected with a sound methodology, regardless of whether they involve judgements, translations, conversations or stories (cf. Cornips and Poletto 2005; Barbiers 2009). In many cases, dialect speakers speak (at least) a regional variety and a national or standard language in addition to their dialect, there is mutual influence between these varieties and the choice between them in a particular conversational setting depends on the conversational circumstances, the interlocutors and the topic of discussion. It is particularly important to avoid accommodation and normative behavior. The way this was solved in SAND was to have the whole interview in the local dialect, which in many cases meant that the fieldworker could not be the interviewer. Rather, one dialect speaker would interview the other one and together they tried to reach a consensus on what was common in their dialect and what was not. Obviously, since dialect variation is a geographical notion it is necessary to control for other social factors that may be a source of variation, such a gender, age, social class, dialect of parents, mobility, and education.

\section{Syntactic doubling}

With this background on dialect syntax research infrastructure in place, we will now look at a specific phenomenon, syntactic doubling, which turns out to be pervasive in many dialects. This phenomenon raises many complex questions. I will concentrate on the question at which levels of a language variation model the properties of doubling should be explained. 


\subsection{Definition}

I define syntactic doubling as in (3).

\section{(3) Syntactic doubling}

A morphosyntactic feature, morpheme, word or phrase is redundantly expressed two or more times within a sentence.

Cases of syntactic doubling include agreement, pronoun doubling, negative concord and many more (cf. Barbiers 2008 for an overview). Two examples are given in (4).

a. Agreement

$\begin{array}{lllll}\text { Zij werk-en } & \text { in } & \text { de } & \text { tuin. } & \text { Standard Dutch } \\ \text { they.PL work.PL } & \text { in the garden }\end{array}$

'They are working in the garden.'

b. Subject pronoun doubling

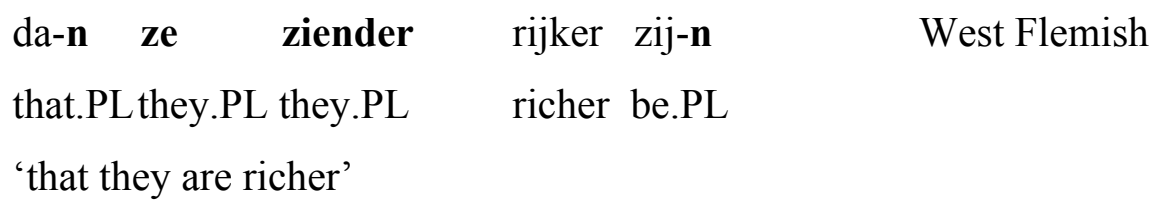

I provisionally use two rules of thumb to identify cases of syntactic doubling. A construction involves syntactic doubling (i) if a sentence $S_{A}$ in language variety $A$ is semantically and pragmatically equivalent to sentence $S_{B}$ in language variety $B$ and $\mathrm{S}_{\mathrm{A}}$ (partially) expresses a constituent twice or more while $\mathrm{S}_{\mathrm{B}}$ expresses it only once, or (ii) if within a language variety a constituent can optionally be doubled without any detectable effect on the semantic or pragmatic interpretation of that sentence.

I choose these restrictive rules to maximize the chance that we are studying genuine syntactic variation, that is two or more structures that have a different surface syntax but an identical interpretation. There are undoubtedly cases in which doubling has an effect on the semantics or pragmatics of the sentences. I put these aside here 
because if they are cases in which different syntax corresponds with different interpretation they are not relevant for the study of syntactic variation. ${ }^{7}$

Whether the doubling of (parts of) constituents is redundant, i.e. does not contribute to the semantic or pragmatic interpretation, is of course not a priori clear but a matter of analysis and debate. It is therefore not always straightforward to decide if a certain construction is a genuine case of doubling.

If we apply the first rule to the presence of verb agreement in French and its absence in Chinese, verb agreement in French qualifies as syntactic doubling. According to the second rule, subject pronoun doubling in certain Flemish dialects is a genuine case of syntactic doubling.

\subsection{Examples of syntactic doubling}

More examples of doubling based on the criteria in 3.1 are given in (5)-(11). Most of the examples are from SAND I (Barbiers et al. 2005) and SAND II (Barbiers et al. 2008) (cf. www.meertens.knaw.nl/sand). For each type of doubling I also give the Standard Dutch equivalent that does not show doubling.
Wh-doubling who think you who I have seen 'Who do you think I have seen?'
a. Wie denk je wie ik heb gezien? Colloquial Dutch
b. Wat denk je wie ik heb gezien?
Colloquial Dutch what think you who I have seen
c. Wie denk je die ik heb gezien? ${ }^{8}$ Regional Dutch who think you REL I have seen
d. Wie denk je dat ik heb gezien? Standard Dutch who think you that I have seen

\footnotetext{
${ }^{7}$ Cf. section 5.1 for a discussion of some pragmatic effects of syntactic doubling. It is possible, of course, that even such semantically or pragmatically differing pairs of syntactic structures are syntactically identical at a more abstract level of analysis, but I will not discuss that possibility in this paper.

${ }^{8}$ This is taken to be a case of doubling because the single operator wie in Standard Dutch (cf. 5d) corresponds to two operators, wie and die in colloquial Dutch.
} 
(6) Negative concord

$\begin{array}{llll}\text { a. T' en danst-ij niemand nie. } & \text { East-Flemish } \\ \text { it NEG dances-he nobody not } & \\ \text { 'Nobody is dancing.' } & & \\ \text { b. Er danst niemand. } & & \text { Standard Dutch } \\ \text { it dances nobody } & \end{array}$

(7) Focus particle doubling

a. Maar één student ken ik maar. Colloquial Dutch

only one student know I only

'I know only one student.'

b. Maar één student ken ik. Standard Dutch

only one student know I

(8) Indefinite article/numeral ONE doubling

a. een vies kindje één Northern Brabantish

a dirty child one

'a dirty child'

b. een vies kindje

Standard Dutch

a dirty child

(9) Preposition doubling

a. Hij zou nooit in het water in springen. Flemish

he would never in the water in jump

'He would never jump into the water.'

b. Hij zou nooit in het water springen. Standard Dutch he would never in the water jump 


\section{(10) HAVE and BE doubling ${ }^{9}$}

a. Ik heb vandaag nog niet gegeten gehad. South-Eastern Dutch

I have today yet not eaten had

'I have not eaten yet today.'

b. Ik heb vandaag nog niet gegeten.

Standard Dutch

I have today yet not eaten

\section{(11) Periphrastic DO ${ }^{10}$}

a. Ik doe even de kopjes afwassen. Southern Netherlandic Dutch

I do a while the cups off-wash

'I am going to wash the cups.'

b. Ik was even de kopjes af.

Standard Dutch

I wash a while the cups off

The pervasive presence of syntactic doubling phenomena in non-standard varieties of Dutch is striking but by no means restricted to the Dutch language area, as the collection of papers in Barbiers, Koeneman, Lekakou and van der Ham (2008) shows. ${ }^{11}$ The frequency and many different types of doubling suggest that doubling is not a peripheral but a central property of syntax and the question is why. ${ }^{12}$

\subsection{Heterogeneity of syntactic doubling}

Syntactic doubling is not a monolithic phenomenon. It is necessary to distinguish between full vs. partial doubling, regional vs. colloquial doubling, optional vs. obligatory doubling, doubling of two functional elements, one functional and one lexical element, or two lexical elements, local vs. distant doubling and apparent vs. real doubling.

\footnotetext{
${ }^{9}$ Unlike many German varieties that have this construction, the relevant Dutch dialects have maintained the preterite. Cf. Koeneman, Lekakou and Barbiers (2011) for discussion.

${ }^{10} \mathrm{Cf}$. Barbiers et al. 2008. In many Dutch dialects this construction does not have to have an habitual interpretation, so that (11a) and (11b) are interpretively equivalent.

${ }^{11}$ See also the doubling phenomena in the descriptions of the projects in the European Dialect Syntax (Edisyn) network (www.dialectsyntax.org).

${ }^{12}$ A separate question is if doubling is more characteristic for substandard languages than for standard languages and if so why, a question I will not go into in this paper.
} 
In full doubling, the two elements are identical, e.g. wie 'who' and wie 'who' in (5a), or in 'in' and in 'in' in (9a). In partial doubling the two elements are not identical but the features of one element are a subset of the features of the other element (cf. Barbiers, Koeneman and Lekakou 2009), e.g., wat 'what' and wie 'who' in (5b) share a Wh-feature, and doe 'do' and wassen 'wash' in (11a) share a verbal feature.

Some syntactic doubling phenomena have a clear geographic distribution, while others seem to involve colloquial speech that is not restricted to a particular dialectal area. For example, periphrastic DO in (11) is largely restricted to the Dutch provinces of Zeeland, Noord-Brabant and Limburg (Barbiers et al. 2008, map 43b), while the geographic distribution of Wh-doubling $(5 \mathrm{a}, \mathrm{b})$ is much less clear (Barbiers et al. 2005, maps 91a,b). The same holds for focus particle doubling (7), for which no geographical restrictions are known.

Many cases of doubling are optional. For example, many speakers of Dutch allow both long Wh-questions with and without doubling (5a), (5b) and (5d), or clauses with and without focus particle doubling $(7 \mathrm{a}, \mathrm{b})$. There are also cases of obligatory doubling, such as the agreement exemplified in (4a).

Doubling of two functional elements is much more common in Indo-European dialects than doubling of two lexical elements (cf. Barbiers 2008). An example of doubling with two functional elements is subject pronoun doubling (4b) and negative concord as in (6a). An example of lexical doubling is verb doubling in verb fronting constructions as it occurs in Spanish and Portuguese (cf. Vicente 2007). The periphrastic DO construction in (11a) is an example of doubling of a lexical element by a functional element.

Syntactic doubling can be local, e.g. agreement between a subject and a finite verb, and it can be long distance, e.g. Wh-doubling in long questions. As was mentioned above, the distinction between local and distant doubling is relevant to distinguish dialect families that allow short Wh-doubling (Italian) from dialect families that allow long Wh-doubling (Dutch).

Finally, cases of apparent and real doubling must be distinguished. Koeneman, Lekakou and Barbiers (2011) argue that HAVE doubling as in (10a) is a case of apparent doubling involving a combination of two distinct lexical items, a copula HAVE (the participle) and an auxiliary HAVE (the finite form). Similarly for BE doubling with unaccusative main verbs. 
Given the heterogeneity of syntactic doubling it is unlikely that a uniform syntactic analysis is possible. While Wh-doubling seems to be a consequence of the properties of dependency chains, agreement seems to involve a more local headspecificier relation. See Barbiers (2008) for an overview of analyses of syntactic doubling.

\section{Syntactic variation and the mental grammar}

This section shows how syntactic variation arises in the interaction between syntax and other modules of the mental grammar.

\subsection{Syntactic doubling as the rule}

Syntactic doubling seems to violate some central hypotheses in modern linguistic research. First, according to the Compositionality Hypothesis commonly attributed to Frege (1892), the interpretation of a clause is the result of the interpretation of the elements in that clause and the way they are combined. Such a hypothesis leaves no room for an element to be expressed twice, as the second occurrence is redundant, it does not contribute to the compositional interpretation and the interpretational system is forced to ignore it, which is quite uncommon otherwise.

Secondly, doubling is problematic from the point of view of Economy (Chomsky 1995), a leading hypothesis in current Minimalist research according to which a syntactic derivation does not contain any superfluous steps or elements. Not only doubling itself is a problem for this hypothesis, but also the fact that doubling is often optional. If a variety can do without doubling, then it is more economical to not have doubling and therefore it should be impossible. ${ }^{13}$

To solve some of these problems I will now argue that, in many cases, doubling is not optional but necessary for semantic interpretation. In clauses that do

\footnotetext{
${ }^{13}$ This argument depends on the definition of economy that is adopted, which is a complex issue. If doubling is found in the underlying syntactic structure and non-doubling is the result of deletion of one of the copies in this doubling structure, then non-doubling is less economical at that level of analysis, as it involves an additional operation. However, if the syntactic part of the derivation of a doubling structure and its non-doubling counterpart is identical, as I argue in the main text, economy considerations are irrelevant at the syntactic level. The question is then if spelling out a copy at PF is less economical than not spelling it out and also if a discrepancy between LF (two copies) and PF (one copy) is less economical than no such discrepancy.
} 
not seem to show overt doubling, there is doubling concealed by a rule according to which one of two identical elements in a local configuration may be phonologically silent. This is an important source of syntactic variation.

To explain the variation that syntactic doubling gives rise to I take the language variation model in (12) as a starting point.

(12) Language variation model



My hypothesis is that syntactic doubling, i.e. doubling in the core syntactic module in (12), is necessary for the mapping of syntactic structure to semantic interpretation, that is the mapping of structures built in the syntactic module to structures at LF (logical form), the level of semantic interpretation in the mental grammar.

A more precise version of the hypothesis is given in (13). See Barbiers (1995) for technical details and further motivation.

\section{(13) Hypothesis}

(i) Local syntactic doubling is necessary to express monadic predication.

(ii) Syntactic doubling is sometimes necessary to express a dyadic relation.

An example of the first configuration is (14). 
(14) Io mangi-o.

Italian

1S eat-1S

'I eat.'

In (14) EAT is a predicate of I. According to (13i), the doubling of the feature $1 \mathrm{~S}$ in (14) is necessary to express this predication relation. If this is true, then doubling is the standard case and no longer problematic. There is no syntactically or semantically superfluous element or step in the derivation and the interpretive system does not need to ignore an element in the syntactic structure.

But now the fact that we do not see syntactic doubling all over the place seems to become problematic. Given that most sentences contain at least one instance of monadic predication, we should be able to observe much more doubling than we actually do. If syntactic doubling is necessary for semantic interpretation, it cannot be optional.

The solution I propose derives from the organization of the mental grammar commonly assumed in generative grammar, more specifically the assumption that syntactic structures built up in the core syntactic component map to the level of semantic interpretation LF and the level of phonological interpretation PF separately. The syntactic configuration built up in syntax for (14) looks like (15), simplifying considerably for ease of exposition.

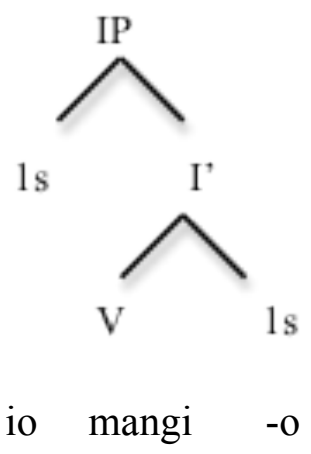

According to (13-i), (15) is interpreted as monadic predication at LF, as required. To account for the fact that the subject pronoun can be silent in (15), I assume the PF rule in (16). 
(16) (i) Redundant feature bundles can/must be (partially) silent at the level of phonological spell out if locally recoverable.

(ii) A feature (bundle) is locally recoverable in a head-spec-complement relation.

This is a general rule and its formulation predicts that we find intralinguistic and cross-linguistic variation. Sometimes a feature bundle must be unpronounced, sometimes it can be unpronounced but does not have to, and sometimes it is only part of the feature bundle that is not expressed. ${ }^{14}$ If this is correct, we expect to find the following language/construction types: ${ }^{15}$

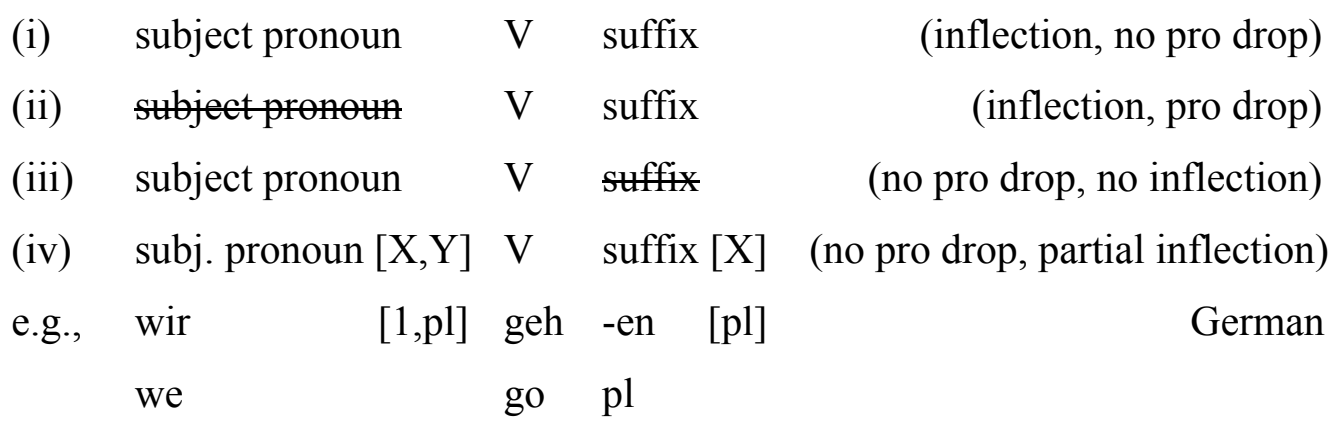

We do not expect to find languages which, under the same syntactic conditions, have neither a subject pronoun nor verbal inflection. ${ }^{16}$ The options in (17) are reminiscent of the patterns we find with negation, i.e. languages that have two negative elements to express clausal negation (e.g., French ne ... pas), languages that only have one negative head (e.g., English not), etc.

If the Jespersen cycle (cf. Jespersen 1917) correctly describes the diachronic change and synchronic variation in clausal negation, then it can be generalized to configurations such as (15). The cycle would then run as follows: (i) Syntax

\footnotetext{
${ }^{14}$ It is unclear if this parametrization can be derived from more abstract properties. For the purposes of this paper I assume that it is a matter of conventionalization, cf. section 5.3.

${ }^{15}$ There is a fifth type of configuration that is predicted to exist. In this configuration, only part of the feature bundle of the pronoun is spelled out but the whole feature bundle of the suffix. It is unclear whether such configurations exist. Thanks to Jeroen van Craenenbroeck for pointing this possibility out.

${ }^{16}$ If Huang (1984) is correct, pro drop in inflectionless languages such as Chinese and Japanese is in fact topic drop and therefore not a counterexample.
} 
uniformly starts with double expression of feature bundles; (ii) PF deletes one of them partially under local recoverability; (iii) If by an independent process a feature becomes completely unexpressed, a restoration process will take place to make that feature visible again. For example, in many Dutch dialects the $2 \mathrm{~S}$ inflection $-s t$ has changed into $-t$, an inflection suffix that is ambiguous between $2 \mathrm{~S}$ and $3 \mathrm{~S}$. Dialects with $-s t$, i.e. Frisian and Groningen dialects, allow pro drop in the second person singular, while dialects with $-t$ do not (cf. Barbiers et al. 2005, map 39b).

\subsection{Syntactic doubling and dyadic relations}

The analysis of pro drop and verbal inflection sketched in the previous section takes variation in this domain to be the result of the interaction between three modules of the mental grammar. For monadic predication the mapping of Syntax to LF requires local doubling of the argument of a predicate and local doubling at PF gives rise to (partial) spell out or silence of locally recoverable features. I will now discuss variation in focus particle doubling to illustrate the dyadic predication situation in (13-ii) in which a predicate requires two distinct arguments to be interpretable. We will see that the quite subtle multiple variation observed follows directly from the assumptions made so far.

The presence of a focus particle on a constituent such as PP in Dutch forces this constituent to occur in a position different from its base position (cf. Barbiers 1995, 2010). This is illustrated in (18). The PP complement [op Jan] 'at John' of the adjective boos 'angry' normally follows the adjective (18a,b), unless the focus particle maar 'only' is attached to it, in which case it has to precede the adjective $(18 \mathrm{c}, \mathrm{d}) .{ }^{17} \mathrm{~A}$ focus particle and a PP can be one constituent, as (18e) shows, so the ungrammaticality of (18c) cannot be due to the impossibility to attach a focus particle to a PP. ${ }^{18}$ We will see that the focus particle has to move to the left of the adjective to find its second argument.

\footnotetext{
${ }^{17}$ If the PP contains a focused DP without a focus particle, as in boos op één jongen 'angry at one boy', this PP can both precede and follow the adjective. This shows that focus makes it possible to move the PP in front of the adjective, while a focus particle makes this necessary.

${ }^{18}$ Like German, Dutch is a verb second language in which maximally one constituent can precede the finite verb in main clauses.
} 
(18) a. Ik ben toen [A boos] [pP op Jan] geweest.

I am then angry at John been

'I was angry at John then.'

b. * Ik ben toen [pp op Jan] [a boos] geweest.

I am then at John angry been

c. *Ik ben toen [a boos] [PP maar op één jongen] geweest.

I am then angry only at one boy been

d. Ik ben toen [Pp maar op één jongen] [A boos] geweest.

I am then only at one boy angry been

e. [pp Maar op één jongen] ben ik boos geweest.

Only at one boy am I angry been

Now there are four ways in colloquial Dutch to express (18d):

(19) Ik ben 'I am'
a. $\quad[\mathrm{PP}$
only at one boy
[A boos]
angry
b. [PP maar op één jongen]
maar [A boos]
only at one boy
only angry
c. $\quad[\mathrm{PP}$
op één jongen]
maar [A boos]
at one boy
only angry
d. $[$ maar
only
[A boos] [PP op één jongen]]
angry at one boy

The data in (19) raise the following questions: (i) Why can one meaning be expressed in four different ways? (ii) Why is the order [Adjective [Focus Particle PP]] impossible while the order [Focus Particle PP [Adjective ]] is possible?

The explanation I propose for (19) is based on the assumption that focus particles such as ONLY are quantifiers, i.e. relations between two sets. Syntactically, such a dyadic relation requires the configuration in (20). 
(20)

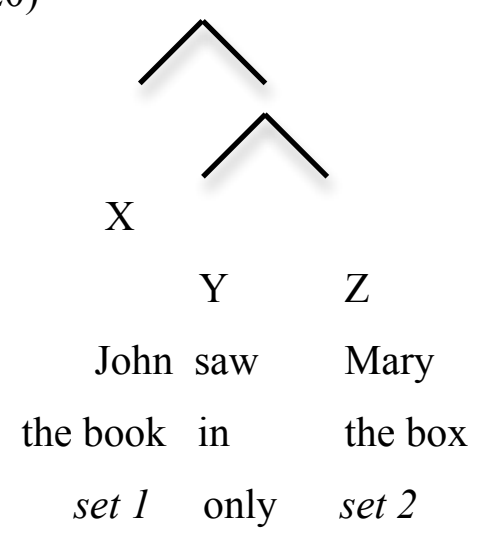

When a focus particle attaches to a PP as in [only [PP at John]], this PP is the first argument of ONLY (i.e., $Z$ in (20)). In this position, ONLY does not have a second argument and therefore cannot be fully interpreted. The second argument of ONLY denotes the set of people that I am angry at. This corresponds to a larger part of the sentence: [only [VP [AP angry [PP at X]]]]. Therefore, for ONLY to be interpretable it needs to occur in two places at the same time: attached to PP and attached to VP.

The configuration before displacement is then as in (21).

[ONLY1 [vp be [AP angry [pP ONLY2 at John]]]]

In order for ONLY1 and ONLY2 to be interpreted as one instance of ONLY taking two arguments (i.e., VP and PP), ONLY2 has to move to ONLY1 (22i). When it does so, it may carry along the PP (22-ii).

(i) [ ONLY2 [ONLY1 [vp be [A angry [pp ONLY2 at John]]]]

(ii) [pp ONLY2 at John [ONLY1 [vp be [A angry [pp ONLY2 at John]]]]]

Under the assumption made above that locally redundant material can be left unpronounced, the four variants of the Dutch sentence can be derived from (22): 
(i) [ONLY2 [ ONLY1 [vp be [A angry [pp ONLY2 at one boy]]]]]

a. mar maar boos op één jongen

(ii) [pp ONLY2 at one boy [ONLY1 [vp [A angry [pp ONLY2 at X.]]]]]

b. maar op één jongen maar boos

c. maar op één jongen boos

d. maar op één jongen maar boos

We have now identified two sources of syntactic variation within the mental grammar, interacting with the fixed principle that a dyadic predicate such as the focus particle ONLY should take its two arguments locally in syntax in order to be interpretable. When ONLY is attached to a constituent it has only one argument. This necessitates doubling of ONLY and movement of one instance of ONLY to the other, optionally carrying along the constituent to which it was attached. It appears that these two movement options, taking place in the core syntactic module as it feeds into semantic interpretation, are the first source of variation, contra the Minimalist assumption that there is no variation in the syntactic module. ${ }^{19}$ In the configurations resulting from this movement ONLY is locally redundant, such that at the level of spell out PF one instance of ONLY can be left unpronounced.

\subsection{Syntactic variation and morphology}

For the sake of completeness, I briefly discuss variation arising at the level of morphology, an important source of morphosyntactic variation. The morphological module is often taken to be part of the PF module in the Mental Grammar layer of the language variation model (12), for example in the framework of Distributed Morphology (Halle and Marantz 1993). This means that morphological processes are taken to operate on the output structures of the core syntactic module. In DM, such processes include head movement (e.g., clitic metathesis), merger (joining two syntactic heads under one categorial head), fusion (fusing two heads into one) and fission (splitting a morpheme into two heads). While these morphological processes are able to capture much of the variation at this level, there is no principled answer to

\footnotetext{
${ }^{19}$ It has often been claimed that this pied piping, i.e. moving a larger constituent than the subconstituent that must be moved, is a source a syntactic variation. A good example is Koopman and Szabolcsi (2000).
} 
the question as to why, e.g., fission, occurs in one construction/language but not in another one. Possibly, conventionalization is the answer here (see section 5.3 for further discussion).

An interesting recent development with potentially more explanatory power is the nanosyntax model (Starke 2009). In this model both lexicalization and morphology operate on the output of the syntax module which works with morphosyntactic features rather than morphemes, similar to Distributed Morphology. Every feature corresponds to a head in the syntactic structure and morphological spell out is phrasal: it can only apply to adjacent heads that form a syntactic phrase, where the number of adjacent heads that are spelled out may vary from word to word and from language to language. A vocabulary item that has all or a superset of the features of a string of adjacent heads is a candidate for vocabulary insertion. The restriction that only adjacent heads can be lexicalized by one word sets very clear limits to the variation that can arise.

\section{Syntactic variation and the other shells of the language variation model}

Working our way from inside out through the language variation model in (12) repeated below in (24) we have seen that syntactic variation may arise at the levels of Syntax and PF. Let us now have a look at the other levels to see to which extent they are relevant for syntactic variation. For each level I take a doubling phenomenon to illustrate its potential relevance. 
(24) Language variation model

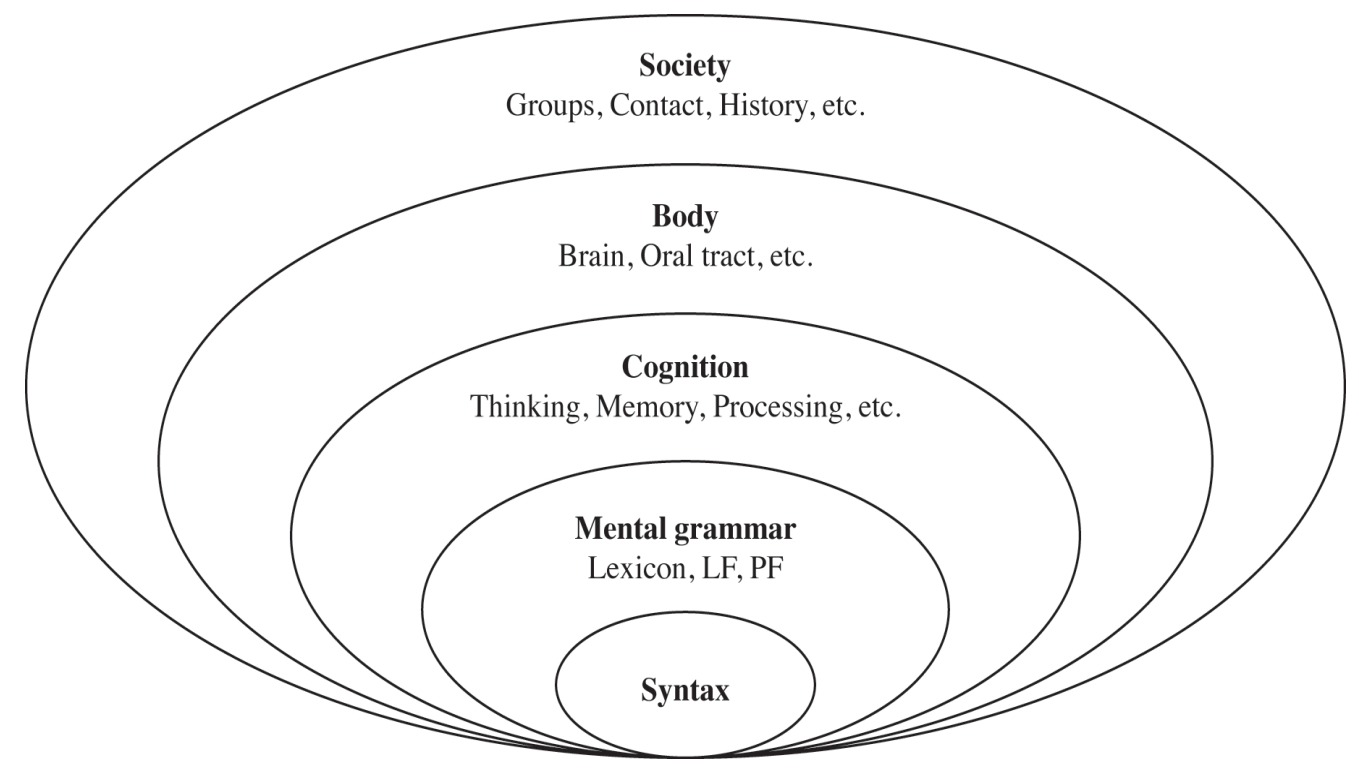

\subsection{Syntactic variation and cognition}

In the previous sections I have discussed doubling constructions that have a semantically and pragmatically equivalent non-doubling counterpart.

Putting aside the difficult question of whether pragmatics belongs to the level of Cognition or rather to the Mental Grammar, I would like to mention two pragmatic effects that syntactic doubling has been claimed to have. Nuyts (1995) has the intuition that subject pronoun doubling (cf. 4b) expresses more empathy from the part of the speaker than the non-doubling variant. This effect has not yet been supported by experimental and systematic research. ${ }^{20}$ If a pragmatic effect of certain types of doubling can be shown to exist, the question is how and why doubling gives rise to exactly that pragmatic effect. This is perhaps slightly more straightforward for another claim that can sometimes be heard, that doubling gives more emphasis or salience to the constituent doubled.

At the level of Processing we can hardly be more precise, as there is little research on the effect of syntactic doubling on processing. Van Haeringen (1939) claims that the complementizer agreement, i.e. (partial) agreement between the subject and the complementizer such as the plural $-n$ suffix on $d a$ in (4b) is in fact anticipation that helps to bridge the distance between subject and finite verb in SOV-

\footnotetext{
${ }^{20}$ The effect has been tested by Eefje Boef (unpublished BA course paper). She did not find any preference for doubling in contexts that required a lot of empathy from the part of the speaker.
} 
languages such as German and Dutch, in which there can be quite some material between the subject and the clause final verb position. Without complementizer agreement, the hearer has to wait until the finite verb is processed to establish which constituent is the subject. With complementizer agreement, processing of the complementizer and the subject is enough to know this. However, this could lead to the expectation that complementizer agreement is absent when the subject and the verb are adjacent, which is not the case. Admittedly, this hypothesis is hard to test, because in many dialects complementizer agreement is not optional.

Another relevant study is Hawkins (2004), who explains the distribution of resumptive pronouns in relative clauses in terms of increasing complexity of processing domains. This explanation is based on Keenan and Comrie's (1977) Accessibility Hierarchy. Keenan and Comrie observed that languages with object relativization also have subject relativization, languages with indirect object relativization also have object and subject relativization, and languages with genitive relativization also have indirect object, direct object and subject relativization. These are one way implications only. For example, we find languages that have subject relativization but no relativization of other constituent types. The Accessibility Hierarchy is summarized in (25):

(25) Accessibility Hierarchy for relativization

$\mathrm{SU}>\mathrm{DO}>\mathrm{IO} / \mathrm{OBL}>\mathrm{GEN}($ Keenan and Comrie 1977)

It is clear that processing complexity, i.e. the structural distance between relative pronoun and the position of the relativized constituent increases when we go down the hierarchy. In (26a), the relative pronoun is right next to the gap of the relativized subject (if there is a gap at all). In (26b) the subject and the verb are intervening, in (26c) as well and the position of the gap relative to the object must be determined, and in (26d) the relativized element whose is embedded in the DP whose mother.
a. the man who __ called
subject relative
b. the man who I called
object relative
c. the man whom I
gave
a book
indirect object relative
d. the man whose mother
I met
genitive relative 
Hawkins (2004) observes that the distribution of resumptive pronouns follows this accessiblity hierarchy. For example, if in a language a resumptive pronoun is grammatical in a subject relative, then the language will also have resumptive pronouns in the other types of relativization. The reverse does not hold. For example, a language can have resumptive pronouns in object, indirect object and genitive relatives but not in subject relatives. Put differently, the lower the position in the Accessibility Hierarchy, the higher the likelihood that a language has resumption for that position. Since a lower position in the hierarchy corresponds to greater processing complexity, we can also say that the likelihood of resumption increases with processing complexity.

While processing complexity is a plausible explanation for this type of doubling, it does not explain cross-linguistic variation in this domain. It does not follow from processing why a resumption pattern like (27) is grammatical in Hebrew but not in English, and it also does not explain why different languages choose different cut off points on the Accessibility Hierarchy.

\subsection{Syntactic variation and the body}

Moving one shell up in the language variation model we arrive at the level of the body. Physical properties of the body have been argued to impose constraints on possible syntactic structures. More specifically, the syntactic module generates hierarchical structures but our oral tract can only produce linear strings. Kayne (1994) argues that this linearization requirement determines many properties of syntactic structure. Only asymmetric structures can be linearized, as a structurally higher position corresponds to a linear position more to the left, according to Kayne's Linear Correspondence Axiom, the mechanism that maps syntactic structure to linear strings.

Following Kayne (1994) Moro (2000) argues that a linearization problem arises when a part of a structure is symmetrical, e.g. two constituents that are equally high in the hierarchy. To make linearization possible, the symmetry must be broken by moving one of the constituents. Since there is a choice to move one constituent or the other, this gives rise to syntactic variation, such as the two variants in $(28 \mathrm{~b}, \mathrm{c})$ derived from the abstract underlying structure (cf. 28a). 
(28) a. BE $[\mathrm{sC}[\text { these pictures }][\text { the cause of the riot }]]^{21}$

b. These pictures are the cause of the riot.

c. The cause of the riot is these pictures.

Also following Kayne (1994), Nunes (2004) argues that a linearization problem arises when a dependency chain contains multiple identical copies, as the linearization algorithm would not be able to distinguish between identical copies. Indeed, multiple occurrences of identical elements in a dependency, such as the Dutch example of Whdoubling in (29a), are exceptional cross-linguistically, while doubling of phrasal constituents such as $(29 \mathrm{~b})$ is claimed to be universally impossible. ${ }^{22,23}$ From this perspective, non-doubling as in $(29 \mathrm{c}, \mathrm{d})$ or partial doubling $(29 \mathrm{e}, \mathrm{f})$ makes the structures acceptable because in such structures there are no identical copies that cause linearization problems.

a. Wie denk je wie ik gezien heb?
who think you who I seen have
'Who do you think I have seen?'

b. *Wat voor boeken heb je wat voor boeken gelezen?
what for books have you what for books read
'What kind of books did you read?'

\footnotetext{
${ }^{21} \mathrm{SC}$ is the abbreviation of Small Clause, a type of constituent the internal structure of which is subject of debate in generative grammar.

${ }^{22}$ According to Nunes (2004), sentences such as (29a) are grammatical because the embedded wie 'who' morphologically reanalyzes with an abstract complementizer and is then no longer a problem for linearization.

${ }^{23}$ With the possible exception of sentences like (i), attested in dialects of Dutch and Afrikaans (cf. Barbiers, Koeneman and Lekakou (2009) and references cited there).
}

(i) Op wie denk je op wie zij verliefd is? At who think you at who she in-love is 'Who do you think she is in love with?' 


c. Wie denk je dat ik gezien heb?
who think you that I seen have
'Who do you think I have seen?'
d. Wat voor boeken heb je gelezen?
what for books have you read
'What kind of books did you read?'
e. Wat denk je wie ik gezien heb?
what think you who I seen have
'Who do you think I have seen?'
f. Wat heb je voor boeken
what have you for books
'What kind of books did you read?'

According to the analyses of Kayne (1994), Moro (2000) and Nunes (2004), variation of the type discussed in this section is thus not syntactic variation in the strict sense, but rather variation that arises when hierarchical structures resulting from fixed syntactic principles are mapped to linear strings. The necessity of this mapping is determined by physical constraints imposed by our body, not by syntactic properties.

\subsection{Syntactic variation and society}

The picture arising above is that the core syntactic module contains a small set of universal principles that do not give rise to syntactic variation. The only apparent exception discussed above are cases where two equivalent movement operations are possible, such as the movement of a focus particle alone or together with the PP to which it belongs (22) or the movement of the subject or the predicate of the small clause (28). But even such cases should not be considered as variation arising by variable principles in the core syntactic module. The possibilities and properties of movement are always the same and variation arises when there is a choice between two equivalent syntactic movement operations.

The interaction between the fixed syntactic principles and the other modules discussed above, the mental grammar, cognition and the body, gives rise to further variation. This variation can be exploited at the level of society, the final level of the language variation model to be discussed. 
Two central observations can be made at this level. First, certain types of syntactic variation interact with sociolinguistic factors while others do not. Secondly, not all languages exploit all syntactic variation allowed by the other modules in the language variation model.

An example of the first observation is the sociolinguistic difference between focus particle doubling and negative concord. As we have seen in section 4.2, focus particles cause the constituent to which they are attached to leave their normal position following an adjective and to move to a position preceding that adjective. The reason for this movement, I argued, is that the focus particle has to find a second argument to be interpretable or, in more traditional terms, to determine its scope. With negative constituents, we find the same situation $(30 a, b)$.

$\begin{array}{lll}\text { a. Jan is <*op Marie }>\text { boos <op Marie }> & \text { geweest. } \\ \text { John is at Mary angry at Mary } & \text { been } \\ \text { b. Jan is <op niemand }>\text { boos <*op niemand }> & \text { geweest. } \\ \text { John is at nobody angry at nobody } & \text { been }\end{array}$

In negative concord languages such as Brabantish, the constituent negation can be doubled by clausal negation, again parallel to focus particle doubling in Dutch $(31 \mathrm{a}, \mathrm{b})$.

a. Jan is op niemand (nie) boos geweest.
John is at nobody not angry been
'John has not been angry at anyone.'
b. Jan is maar op één student (maar)boos geweest.
John is only at one student only angry been
'John has been angry at only one student.' 24

When the negative constituent is nominal instead of a PP, an interesting phenomenon arises. In certain Brabantish dialects such as Aarschots (Pauwels 1958; Barbiers et al. 2008, section 4.3.2.13) the $n$ - of the negative constituent can be dropped when the

\footnotetext{
${ }^{24}$ Like in English, the focus particle in Dutch can also occur inside the PP, but this variation is irrelevant here.
} 
clausal negation is present. This is illustrated in (32a). Again, this is parallel to focus particle doubling (32b).

a. Jan heeft (n-)iemand no nie
John has nobody/somebody not

Together, (31) and (32) show that negative concord and focus particle doubling behave parallel in that one of the negative morphemes or focus particles can be omitted in configurations where the omitted morphemes are locally recoverable.

However, there is a clear sociolinguistic difference between the two. While ndrop in negative concord is restricted to Brabantish dialects in the Belgian province of Antwerp (Barbiers et al. 2008, map 59a), no such geographical restrictions have been reported for focus particle drop. This raises the more general question as to why certain syntactic variables are sensitive to sociolinguistic specialization while others are not. This is a little investigated topic. For the case at hand, we could speculate that frequency may play a role. It is plausible that constituent negation is more frequent than modification of constituents by focus particles. Perhaps, then, a syntactic variable needs to pass a certain frequency threshold to be a candidate for sociolinguistic specialization. Focus particles would be below this threshold while constituent negation would be above it.

The second question, why not all languages use all the variation permitted by the language variation model, may also receive an explanation at the level of society. A distinction between impossible and possible structures, and within the latter class between realized and unrealized structures, is helpful here (cf. Barbiers 2009). This distinction is commonly accepted in the domains of phonotaxis and morphology. The phonotactic system of a language defines the possible words of that language, but not all possible words are realized. For example, the word pert obeys all phonotactic rules of Dutch but does not exist, i.e. it does not have a conventionalized meaning. Similarly, zoveelheid 'so-many-ness' (i.e. a certain quantity) is a possible but not (yet) existing morphologically complex word of Dutch. 
The notion of possible but unrealized word is unproblematic in these domains because we know that conventionalization is crucial in the lexicon. Once we allow a certain amount of conventionalization of syntactic structures too, a position that is more and more common both in generative grammar (cf. Hale and Keyser 1993 for an example) and in frameworks like Cognitive Grammar (Langacker 1990), we can capture the fact that not all languages/speakers use all the syntactic variants generated by the language variation model. Put differently, the non-sociolinguistic layers of this model define the syntactic variation space, and language users make their choice from the available variants, a choice which is partly determined by the social environment during acquisition.

\section{Conclusion}

The goal of this paper was to demonstrate the viability and potential fruitfulness of a language variation model according to which the core syntactic module only consists of a small set of fixed universal principles. Syntactic variation within the syntactic module can only arise if two equivalent structures can be derived with the same mechanism. All other syntactic variation arises in the interaction between the output of the syntactic module and the other layers of the language variation model, i.e. the Mental Grammar including Lexicon, PF and LF, cognitive modules such as memory and processing, physical constraints imposed by the body such as the necessity to linearize hierarchical structures and mechanisms at the level of society that determine the social distribution of syntactic variables. It was shown that all these levels together can explain many properties of the variation found in syntactic doubling constructions. The most important advantage of this language variation model is that it avoids the tendency found in much generative work to explain syntactic variation by syntactic principles exclusively (cf. Jackendoff 2002 for a similar point).

\section{References}

Barbiers, S. 1995. The Syntax of Interpretation. PhD Dissertation Leiden. The Hague: HAG.

Barbiers, S. 2008. "Microvariation in Syntactic Doubling. An Introduction". Microvariation in Syntactic Doubling (= Syntax and Semantics, 36) ed. by S. 
Barbiers, O. Koeneman, M. Lekakou and M. van der Ham, 1-34. Bingley: Emerald.

Barbiers, S. 2009. "Locus and limits of syntactic microvariation”. Lingua 119:11. 1607-1623.

Barbiers, S. 2010. "Focus particle doubling". Structure Preserved. Studies in Syntax for Jan Koster ed. by M. de Vries and J.W. Zwart, 21-30. Amsterdam/Philadelphia: John Benjamins.

Barbiers, S., H. Bennis, G. De Vogelaer, M. Devos and M. van der Ham. 2005. Syntactic Atlas of the Dutch Dialects, Volume I (= SAND I). Amsterdam: Amsterdam University Press.

Barbiers, S., J. van der Auwera, H. Bennis, E. Boef. G. De Vogelaer, M. van der Ham. 2008. Syntactic Atlas of the Dutch Dialects, Volume II (= SAND II). Amsterdam: Amsterdam University Press.

Barbiers, S., O. Koeneman, M. Lekakou and M. van der Ham, eds. 2008. Microvariation in Syntactic Doubling. (= Syntax and Semantics, 36) Bingley: Emerald.

Barbiers, S., Koeneman, O. and Lekakou, M. 2009. "Syntactic doubling and the structure of wh-chains". Journal of Linguistics 45. 1-46.

Chomsky, N. 1995. The Minimalist Program. Cambridge, Mass.: MIT Press.

Chomsky, N. 2005. “Three Factors in Language Design”. Linguistic Inquiry 36. 1-22.

Cornips, L. and C. Poletto. 2005. "On standardising syntactic elicitation techniques. PART I'. Lingua 115:7. 939-957.

Fernández-Ordóñez, I. 2010. "La Grammaire dialectale de l'espagnol à travers le Corpus oral et sonore de l'espagnol rural (COSER)". Corpus 9, special issue La Syntaxe du Corpus/Corpus Syntax ed. by M. Olivieri. 81-114.

Frege, G. 1892. “Über Sinn und Bedeutung”. Zeitschrift für Philosophie und Philosophische Kritik NF 100. 25-50.

Haeringen, C. van. 1939. “Congruerende voegwoorden”. Tijdschrift voor Nederlandse Taal- en Letterkunde 58. 161-176.

Hale, K. and S. Keyser. 1993. "On argument structure and the lexical expression of syntactic relations". The View from Building 20: Essays in linguistics in honor of Sylvain Bromberger ed. by K. Hale and S. Keyser, 53-109. Cambridge, Mass.: MIT Press. 
Halle, M. and A. Marantz. 1993. "Distributed morphology and the pieces of inflection”. The View from Building 20: Essays in linguistics in honor of Sylvain Bromberger ed. by K. Hale and S. Keyser, 111-176. Cambridge, Mass.: MIT Press.

Hawkins, J. 2004. Efficiency and Complexity in Grammars. Oxford: Oxford University Press.

Huang, J. 1984. "On the Distribution and Reference of Empty Pronouns". Linguistic Inquiry 15. 531-574.

Jackendoff, R. 2002. Foundations of Language. Brain, Meaning, Grammar, Evolution. Oxford: Oxford University Press.

Jespersen, O. 1917. Negation in English and other languages. Copenhagen: A.F. Høst.

Kayne, R. 1994. The Antisymmetry of Syntax. Cambridge, Mass.: MIT Press.

Keenan, E. and B. Comrie. 1977. "Noun Phrase Accessibility and Universal Grammar”. Linguistic Inquiry 8. 63-99.

Koeneman, O.N.C.J., Lekakou, M. and Barbiers, S. 2011. "Perfect Doubling". Linguistic Variation 11:1. 35-75.

Koopman, H. and A. Szabolcsi. 2000. Verbal complexes. Cambridge, Mass.: MIT Press.

Kunst, J.P. and F. Wesseling. 2011. "The Edisyn search engine”. Oslo Studies in Language 3:2 Language Variation Infrastructure ed. by J. B. Johannessen. 63-74.

Langacker, R., 1990. Concept, Image Symbol: The Cognitive Basis of Grammar. Berlin/New York: Mouton de Gruyter.

Moro, A. 2000. Dynamic Antisymmetry. Movement as a symmetry breaking phenomenon (=Linguistic Inquiry Monograph Series 38) Cambridge, Mass.: MIT Press.

Nunes, J. 2004. Linearization of Chains and Sideward Movement (= Linguistic Inquiry Monograph Series 43) Cambridge, Mass.: MIT Press.

Nuyts, J. 1995. "Subjectpronomina en dubbele pronominale constructies in het Antwerps". Taal \& Tongval 47. 43-58.

Pauwels, J. 1958. Het dialect van Aarschot en omstreken. Brussel: Belgisch Interuniversitair Centrum voor Neerlandistiek.

Poletto, C. and Pollock. J.-Y. 2004. “On Wh-clitics, Wh-doubling in French and some 
North Eastern Italian dialects". Probus 16. 241-27.

Starke, M. 2009. "Nanosyntax: A short primer to a new approach to language". Nordlyd 36:1.

Vicente, L. 2007. The syntax of heads and phrases. A study of verb (phrase) fronting. PhD dissertation Leiden. LOT Dissertations 154. 